\title{
El cine y la enseñanza del arte en Brasil: una mirada a concepciones y experiencias modernistas
}

\author{
Cinema and the teaching of art in Brazil: a look at modernist \\ conceptions and experiences
}

Sidiney Peterson F. de LIMA ${ }^{1}$. Instituto de Artes- UNESP (Brasil). s.lima87@yahoo.com

Resumen: En este trabajo se busca presentar y discutir algunas prácticas desarrolladas en el campo de formación de profesores de arte, en el ámbito del Curso Intensivo de Arte en la Educación (CIAE), apuntando, especialmente, la presencia del cine como lenguaje artístico importante en la trayectoria de formación. En primer lugar, a partir de una contextualización histórica, teniendo como base los estudios de la investigadora Ana Mae Barbosa (2015), realizamos una discusión acerca de las relaciones entre cine y educación, considerando las lecturas acerca del cine a través de proyectos en el período del Movimiento Escuela Nueva (1920,1930), destacando las acciones desarrolladas por la poetisa y educadora Cecilia Meireles. Con el presente trabajo se tiene como finalidad ampliar las ideas y percepciones acerca de la historia del cine y la educación en Brasil, principalmente en el campo de formación de profesores de arte, considerando la experiencia CIAE.

Palabras clave: cine, arte en la educación, historia, formación de profesores/as, CIAE

\footnotetext{
1. El trabajo presentado aquí es un desarrollo de la investigación doctoral, llevada a cabo entre los años 2016 y 2020 , en el Instituto de Artes-UNESP, sobre el "Curso Intensivo de Arte na Educação e a formação de especialistas em arte na educação (1961-1981). Investigación que fue apoyada a través del processo n 2016/05781-9, de la São Paulo Research Foundation (FAPESP). Doctor en Artes, por el Instituto de Artes-UNESP/ Brasil. Director de Relaciones Internacionales de la "Federação de Arte/ Educadores do Brasil - (FAEB) bienio 2019-2020. Realiza nvestigaciones sobre Historia del Arte/Educación en Brasil con énfasis en el "Movimento Escolinhas de Arte (MEA)"; formación de profesores del arte en Brasil, con énfasis en el "Curso Intensivo de Arte na Educación (CIAE)"; experiencias de enseñanza y aprendizaje de artes, en Brasil y América Latina.
} 
LIMA / El cine y la enseñanza del arte en Brasil: una mirada a concepciones y experiencias modernistas.

\begin{abstract}
This paper aims to present and discuss some of the practices developed in the field of art teacher training, within the scope of the Intensive Course of Art in Education (CIAE), pointing out, in particular, the presence of cinema as an important artistic language in the trajectory of formation. Initially, based on a historical context, based on the studies of researcher Ana Mae Barbosa (2015), we conducted a discussion about the relations between cinema and education, considering the readings about cinema through projects in the period of the New School Movement $(1920,1930)$, highlighting the actions developed by the poetess and educator Cecília Meireles. With the present work we aim to broaden the ideas and perceptions about the history of cinema and education in Brazil, especially in the field of art teacher training, considering the CIAE experience.
\end{abstract}

Keywords: cinema, art in education, history, teacher training, CIAE.

Resumo:Nestetrabalhobusca-se apresentare discutiralgumas práticas desenvolvidas no campo de formação de professores de arte, no âmbito do Curso Intensivo de Arte na Educação (CIAE), apontando, especialmente, a presença do cinema como linguagem artística importante na trajetória de formação. Inicialmente, a partir de uma contextualização histórica, tendo como base os estudos da pesquisadora Ana Mae Barbosa (2015), realizamos uma discussão acerca das relações entre cinema e educação, considerando as leituras acerca do cinema através de projetos no período do Movimento Escola Nova $(1920,1930)$, com destaque para as ações desenvolvidas pela poetisa e educadora Cecilia Meireles. Com o presente trabalho tem-se como finalidade ampliar as ideias e percepções acerca da história do cinema e educação no Brasil, principalmente no campo de formação de professores de arte, considerando a experiência CIAE.

Palavras-chave: cinema, arte na educação, história, formação de professores/as, CIAE

\title{
Primeras palabras
}

Para saber hay que tomar posición. No es um gesto sencillo. Tomar posición es situarse dos veces, sobre dos frentes que conlleva toda toda posición, puesto que toda posición es, fatalmente, relativa (...). Para saber, hay que saber lo que quiere pero, también, hay que saber donde se sitúa nuestro nosaber, nuestros miedos latentes, nuestros deseos inconscientes por lo tanto.

Didi-Huberman (2008; p. 11)

La historia de la enseñanza del arte en Brasil, dice Ana Mae Barbosa, "ha pasado por fases que se suman entre sí: se intercalan, raramente dialogan y operan en cascada, en capas" (Barbosa, 2015, p. 18). La imagen que nos ofrece la autora es muy importante para una posible localización de los entendimientos, prácticas y 
acciones del cine en la enseñanza de las artes, en la historiografía del arte en la educación ${ }^{2}$ en el contexto brasileño.

En Brasil, el interés por un cine relacionado con la educación no es reciente, como tampoco son los estudios e investigaciones sobre el cine, sus usos y potencialidades para la educación . Históricamente, educadoras, educadores e intelectuales defendieron la introducción del cine como herramienta pedagógica, en diferentes épocas, fundamentadas en distintas concepciones y objetivos del uso y de la producción del cine en el contexto educativo. Ante una posible historia de las relaciones entre cine y educación, en Brasil, destacamos algunos aspectos relevantes para situar la perspectiva explorada en este artículo, cuál es, de la importancia de saberes históricos, aquí sobre el cine y la educación, para un pensar acerca de los fundamentos y perspectivas, contemporáneas, en el trabajo con imágenes de artes y culturas visuales.

Como se mencionó, diferentes educadoras y educadores defendieron la inserción del cine en el contexto educativo. En los años 1920 y 1930, el Movimiento Escuela Nueva ${ }^{3}$ reunió, en la segunda década del siglo XX, un grupo de educadoras y educadores, intelectuales y políticos que se conocieron como Pioneros de la Educación entre los que destacamos Cecilia Meireles, Edgar Sussekind de Mendonça, Fernando de Azevedo, Anísio Spinola Teixeira, Manuel B. Lourenço Filho, Francisco Venâncio Filho, Jonathas Serrano, Edgar Roquette-Pinto. Educadora/e(s) que, como señala María Lúcia Spedo Hilsdorf, defendieron las "transformaciones en el sentido de modernización de la escuela brasileña" (Hilsdorf, 2015, p. 79, traducción del autor $\left.^{4}\right)$. Es de ese contexto que, inicialmente, destacamos la educadora y poetisa Cecilia Meireles, como una de las defensoras del cine, como importante instrumento educativo.

\section{El cine educativo en Brasil de los años 1920 y 1930: Cecilia Meireles, una defensora de la educación infantil y de las artes en el contexto escolar}

En el Redesenhando o desenho: educadores, politica e história (2015), Ana Mae Barbosa analiza, a partir, principalmente, de artículos publicados en diarios de la época, el apoyo de la poetisa y educadora Cecilia Meireles sobre la Educación

\footnotetext{
2. Edgar-Roquete Pinto, por ejemplo, constataba, en 1936, una "función pedagógica de los medios de comunicación de masas" (Fabris, 2008, p. 118, t. a.), sin contar "las numerosas películas que retratan el ambiente escolar o la figura del profesor, o incluso la práctica de exhibir películas o trechos en el aula" (Almeida, 2017, p. 2, t. a.).

3. Para profundizar las lecturas acerca de este movimiento y sus discursos pedagógicos, políticos y culturales conferir Vidal (1996); Hilsdorf (2015); Kulesza (2002). Sobre el Movimiento Escuela Nueva y el cine, conferir Paixão et all (2011); Matte (2010).
}

4. A partir de este punto utilizamos las siglas t.a. para referirnos a las traducciones realizadas por el autor. 
LIMA / El cine y la enseñanza del arte en Brasil: una mirada a concepciones y experiencias modernistas.

Infantil, así como al proyecto de enseñanza de artes (dibujo) y valorización, además de la literatura y el cine, de las artes plásticas y del teatro (Barbosa, 2015, t. a.). Siguiendo la investigación emprendida por Barbosa, sobre artes en la escuela, dice la autora que "Cecilia Meireles escribió, sólo en el diario A Manhã nueve artículos sobre el asunto, entre agosto de 1941 y enero de 1942, y creo que escribió mucho más entre 1929 y 1931 en el Diario de Notícias, pues este período fue de intensa libertad de pensar" (2015, p. 237, grifos de la autora, t.a.).

Sobre el cine educativo, Cecilia Meireles escribió que este es "uno de los elementos de inmediata importancia en las escuelas de hoy" (citado en Barbosa, 2015, p. 240 , t.a.). La educadora defendía la idea de inserción del cine educativo como herramienta importante para un "aprender viendo", conforme podemos verificar en una entrevista concedida por Cecilia Meireles, al Jornal do Comércio, edición del 20 de agosto de 1929, en que la educadora afirma que "es el cine educativo, al lado del 'learning by doing' de las escuelas americanas, se podría inscribir también el 'learning by seeing', porque, dice la educadora, "en realidad, nosotros y los niños, también aprendemos viendo" (citado en Barbosa, 2015, p. 240, t. a.).

Cecilia Meireles, así como otros educadores del Movimiento Escuela Nova, en Brasil, dio mucha importancia al cine, aunque, como señala Ana Mae Barbosa, las acciones promovidas por la educadora y el grupo han "enfrentado una seria oposición de los conservadores que hacían las peores acusaciones contra el cine" (Barbosa, 2015, p. 248, t.a.), actitud que, "años después se harían a la televisión por banalizar la educación y la computadora por subyugar al alumno"(Barbosa, 2015, p. 248-249,t.a.)

En defensa de la introducción del cine en la escuela, Cecilia Meireles afirmaba que el nuevo instrumento de enseñanza (Barbosa, 2015) "no obedece, pues, a un capricho de la moda o a cualquier intención sólo decorativa", sino a una "necesidad natural a la que las circunstancias del progreso humano pueden atender" (citado en Barbosa, 2015 , p. 241, t.a.). Interesaba a Meireles, en esa inserción del cine en el aula, la manera cómo los profesores pudieran trabajar con esta herramienta "instructiva". Lo importante, destaca Cecilia Meireles, es que profesores y estudiantes "aprecien" con el cine (citado en Barbosa 2015, p. 240, t.a.).

Así, en aquel momento, parafraseando a Rosana Catelli, con las imágenes, presentes en el cine, pero también en las ilustraciones de revistas, en las exposiciones y acervos de museos, en las conferencias científicas en las escuelas y en la publicidad, se buscaba "formar una cultura visual y formas institucionalizadas del ver" (Catelli, 2005, s/p., t.a.). Con "las nuevas tecnologias" e "instituciones" la intención era, según Catelli, crear "hábitos de ver múltiples, que se alimentaban mutuamente y educaban a la sociedad para esta nueva cultura de intensa circulación de imágenes" (Catelli, 2005, s/p., t.a.). El cine educativo, defendido por Cecilia Meireles, entre otros educadores, puede, de acuerdo con esta autora "ser insertado en ese proceso de una serie de fenómenos correlatos que eligieron la imagen como 
agente desencadenante de transformaciones sociales y culturales, de consumo y de estímulo" (Catelli, 2005, s/p., t.a.).

En ese sentido, es importante destacar el papel de Cecilia Meireles en la difusión de propuestas que buscaban poner en foco la relevancia del cine educativo. Francisco Venâncio Filho, como Cecilia Meireles y otros participantes del Movimiento Escuela Nueva, también defendía el cine educativo. En 1941 escribió, en contraposición la idea de que el cine "evita el esfuerzo de la inteligencia" (Filho, 1941, p. 48, t.a.) que "el cine educa siempre" (Filho, 1941, p. 48, t.a.).

Para Cecilia Meireles el cine es importante y educa, pues "tras una proyección, el recuerdo de las imágenes vistas es más nítida y más duradera que de las mismas imágenes ofrecidas por medio de una [otra] lección, e incluso por la simple presentación de figuras" (citado en Barbosa, 2015, p. 240, t.a.). Según el pensamiento de Cecilia Meireles, la experiencia de "ver" una película es muy importante para que los saberes "se hagan con más facilidad y provecho" (citado en Barbosa, 2015, p. 240, t.a). ¿Qué ver tiene relación con el saber? Pensamos que aquí cabe ampliar la cuestión tomando en cuenta las provocaciones propuestas por Inés Dussel (2014): ¿Qué nociones hemos establecido, históricamente, entre el ver y el saber? ¿Qué otras relaciones podemos pensar? Son provocaciones que nos llevan a reflexionar sobre por qué y cómo hemos trabajado con imágenes en el aula, qué esperamos y cómo ampliar las relaciones entre el ver y saber?

Retomando las concepciones de Cecilia Meireles sobre el cine, las proyecciones de imágenes en movimiento, pero ella también defendía la idea de trabajar con imágenes fijas, que en su concepción se caracterizaban como importantes instrumentos pedagógicos. Para la educadora, "mucha cosa, si no casi todo, puede ser aprendido sólo por el cine" (citado en Barbosa, 2015, p. 243, t.a.). Es posible, dice Meireles, a partir de trabajos con imágenes un aprendizaje que esté relacionada con "la imaginación" (citado en Barbosa, 2015, p. 240, t.a).

Conforme buscamos presentar, hasta aquí, el cine educativo, en las décadas de 1920 y 1930, fue asunto importante en las agendas educativas, de manera que, a finales de la década de 1920 el cine educativo vino a ser tema de exposición, en la ciudad de Río de Janeiro (RJ). Una estrategia que, creemos, buscaba un convencimiento acerca de la importancia del cine en la educación, así como la ampliación del debate sobre la temática, por medio de la exposición que ocurrió en la escuela José de Alencar, en el Largo do Machado (barrio de la ciudad del Rio de Janeiro) y tuvo como organizadora, la entonces subdirectora técnica de la Instrucción Pública, Cecilia Meirelles. Jonathas Serrano, personaje importante en la defensa y sistematización del cine educativo en Brasil, fue responsable de promover dicha exposición ${ }^{5}$.

5. Para leer, en su totalidad, el testimonio de Cecilia Meireles acerca de los preparativos, así como sobre la repercusión de 
LIMA / El cine y la enseñanza del arte en Brasil: una mirada a concepciones y experiencias modernistas.

Concordamos con Barbosa (2015) cuando la investigadora y arte/educadora afirma que el cine, en los discursos escogidos, fue "valorizado en la educación como facilitador", pero es importante subrayar que Cecilia Meireles ya comprendía el papel "cultural" del cine en el ambiente escolar, conforme se puede verificar en la afirmación de la educadora sobre la existencia de "una generalizada cultura popular que en gran parte se debe a esa difusión del conocimiento que el cine-diversión insensible pero progresivamente hace". Además de "instructivo, el cine puede ser considerado hasta curativo, cuando (...) presenta un Charles Chaplin" (citado en Barbosa, 2015, p. 251, t.a.), cuando está presente en la escuela inscrito como un "learning by seeing".

El cine en la formación de profesores/as modernistas del arte: experiencias en el Curso Intensivo de Arte en la Educación (1960-1970)

Fue a partir de 1961 que la "Escolinha de Arte do Brasil" (EAB) ${ }^{6}$, en la ciudad de Río de Janeiro/Brasil, pasó a ofrecer el Curso Intensivo de Arte en la Educación $(\mathrm{CIAE})^{7}$, un curso que, de acuerdo con la arte/educadora y coordinadora técnica y pedagógica del CIAE, Noemia Varela, puede ser pensado como una manera de buscar "la más adecuada respuesta para la formación del profesor en la Escuela" (Varela, 1972, p. 11, t.a.) trabajando siempre "en el sentido de despertar la capacidad creadora del alumno" (Varela, 1972, p. 12, t.a.).

Comprendemos el CIAE como un marco histórico en la formación de profesores/ as de artes em la educación en Brasil. Este entendimiento se da a partir de nuestros estudios, fundamentados, entre otros trabajos, en las investigaciones acerca de los procesos de formación de profesores de artes, de la arte-educadora Ana Mae Barbosa que se refiere al CIAE como "los primeros cursos regulares, frecuentes, continuados, para la formación de profesores modernistas de Arte en Brasil" (2015, p. 394, t.a.). Nuestro entendimiento y, por tanto, línea de trabajo en nuestra investigación, sobre el CIAE, es de un curso que promovió una "ruptura" en el modo de pensar, organizar y realizar la formación de profesores de artes en Brasil, provocando profundas transformaciones teórico/prácticas que resonaron en la enseñanza de artes en escuelas públicas y privadas, principalmente cuando verificamos que, como afirma Noemia Varela, se trata de un "curso no oficializado que viene preparando profesores para [actuar en] escuelas gubernamentales” (Varela ,1972, p. 10, t.a.).

esta exposición cf: Barbosa (2015)

6. Sobre la creación, fundamentos teóricos y metodológicos de la Escolinha de Arte do Brasil cf LIMA (2012, 2014, 2017a, 2017b, 2019, 2020); AZEVEDO (2000); COSTA (1990).

7. Actualmente realizamos investigación de doctorado, con beca de investigación FAPESP, proceso n ${ }^{\circ}$ 2016/ 05781-9, sobre el Curso Intensivo de Arte en la Educación (CIAE), ediciones de 1960 a 1980. La investigación se inició en 2016. 
Cuando apuntamos al CIAE como un marco en la historia de la formación de profesores de arte en Brasil, partimos de nuestros estudios en que verificamos el CIAE como el primer curso de formación a trabajar con artes plásticas, teatro, expresión corporal y música, diferente de los cursos de formación ofrecidos en la época, como los de las Escuelas de Bellas Artes- Cursos de formación de profesores de diseño. Es importante destacar que cada lenguaje artístico era ofrecido por una educadora o educador especialista. También es importante destacar la presencia de artistas en ese proceso de formación. Otros aspectos pueden ser señalados, pero en este momento, deseamos enfatizar la presencia del cine en la formación ofrecida en el CIAE, analizando cómo se trabajaba y cuáles las relaciones establecidas entre el ver y el saber, en este curso.

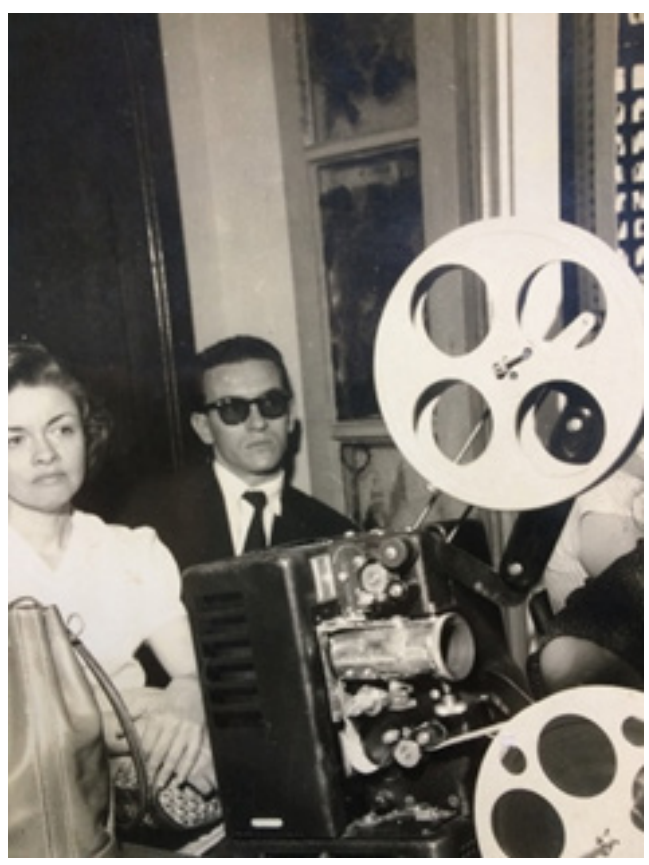

Figura 1: Proyección de películas en clase en el CIAE. Curso a cargo del Profesor Onofre Peinado. 1962. Fuente: Colección Escolinha de Arte do Brasil (EAB).

En el "Programa de Actividades" del "Curso Intensivo de Arte na Educação", realizado entre el 10 de enero y el 24 de febrero de 1961, verificamos, como justificación del curso, la "necesidad de una mayor conciencia de la importancia del arte en la educación" ". Esta primera edición del curso se organizó de manera que los estudiantes tuvieran contacto con "ideas", "teorias" y "prácticas" de las "principales tendencias del arte y de la educación"10.

8. Curso Intensivo de Arte na educação. Programa de Atividades [S. I]: CIAE, 1961, 11 fls. (Colección EAB). Escrito a máquina.

9. Idem

10. Idem 
LIMA / El cine y la enseñanza del arte en Brasil: una mirada a concepciones y experiencias modernistas.

Noemia Varela, según destaca Lucimar Bello Frange, "sustancia filosófica, teórica y constructora de las ideas del CIAE" (Frange, 2001, p. 194, t.a.) desde aquella primera edición del CIAE, pensó en el curso como un camino para la creatividad, una posibilidad de formación de profesores creativos (Varela, 1986). En ese sentido, elaboró un programa de formación que trabajaba, además de los lenguajes ya mencionados arriba, con literatura, arquitectura, con cine. En su visión, el CIAE, "es sólo el comienzo de un largo proceso de preparación del profesor creativo" (Varela, 1986, p. 18, t.a.), así, reflejó que, la diversidad de lenguajes artísticos abordados a lo largo del curso se constituyese como "fuente de renovación y transformación" (Varela, 1986, p. 18, t.a).

Específicamente sobre el cine en la formación ofrecida en el CIAE, en el programa de actividades, de la edición del CIAE de 1961, consta el ofrecimiento de conferencias denominadas "Cine en la Educación" a cargo del crítico de cine Antônio Moniz Vianna (1924- 2009) señalado como responsable por la "formación de generaciones de críticos a través de los textos publicados en el extinto [diario] Correio da Mañana"11. Para tener idea del pensamiento de Antonio Moniz Vianna acerca del cine y de las formas de aprendizaje de ese arte, en entrevista, el crítico, afirma que el cine se aprende "viendo películas. Y leyendo"12.

Lo que deseamos destacar aquí es la propuesta, por el CIAE, de Noemia Varelaresponsable por la construcción del programa de estudios del CIAE, entre $1960 \mathrm{y}$ 1980, período que ejerció la función de coordinadora pedagógica del curso- de una formación que tenía "la creatividad como caminho" (Varela, 1972, p. 7, t.a.) para la construcción de "prácticas creativas a través de las artes plásticas, danza, teatro, música y otras formas de expresión artística” (Varela, 1972, p. 7, t.a.) como el cine.

En la edición del Curso Intensivo de Arte en la Educación, realizada entre el 2 de mayo y el 31 de julio de 1962, además de las conferencias con Antonio Moniz Vianna, el curso pasó a ofrecer proyecciones de películas con la finalidad de "promover debates"13 que fue orientado por el profesor de dibujo de la Escuela de Bellas Artes de Río de Janeiro Onofre Penteado, por la educadora y psicóloga Maria Helena Novaes Mira y por el artista y periodista Augusto Rodrigues ${ }^{14}$.

11. Couto, José Geraldo. Moniz Vianna ilumina o cinema com paixão. Ilustrada. Folha de São Paulo, 06 de novembro de 2004. Disponible en: https://www1.folha.uol.com.br/fsp/ilustrad/fq0611200419.htm. Acceso en: 09 de agosto de 2018.

12. Vianna, Antonio Moniz. Entrevista concedida a Evaldo Mocarzel. Críticas. São Paulo, 06 de marzo de 2006 (publicada en 2013 en www.criticos.com.br). Disponible en: http://criticos.com.br/?p=1097. Accesso en: 09 de agosto de 2018.

13. Curso Intensivo de Arte na educação. Programa de Atividades [S. I]: CIAE, 1961, 11 fls. (Colección EAB). Escrito a máquina.

14. Artista y periodista pernambucano, Augusto Rodrigues fue, en 1948, uno de los creadores de la Escuela de Arte de Brasil (EAB). 
Con la presencia del cine -al igual que de otras expresiones artísticas-, dice Noemia Varela, el CIAE "busca actuar con prontitud y de la manera más adecuada posible para el cambio", que el arte-educadora entendía ser posible, sólo, a través de "una actividad particular del género humano- el arte" (Varela, 1972, p. 5, t.a.), incluso el cine, como importante instrumento pedagógico para la formación de profesores de artes.

Como podemos comprobar, el cine, así como apuntado por Ana Mae Barbos acerca de los discursos escolanovistas, en el CIAE, también se caracterizaba como un medio, tenía importancia como "un facilitador" de aprendizajes sobre contenidos distintos que no el propio cine, una práctica que no se termina, en Brasil, con el CIAE, como señala Rogério de Almeida (2017), la defensa por un uso del cine, en aulas, como herramienta para fines educativos, "pedagogizando el cine" (Almeida, 2017 , p. 5, t.a.) aún permanecen en la actualidad. Por otro lado, hay, en consonancia, otros modos de pensar y trabajar con el cine en el contexto educativo, entre ellos, Almeida (2017) destaca publicaciones que trabajan con la perspectiva de cine como conocimiento y otras con el cine como revelador de realidades, productor de los sentidos (Almeida, 2017) y, aún, los trabajos que parten del "dimensionamiento de los aspectos sensibles y creativos del cine" (Almeida, 2017, p. 5-6, t.a.).

Ante tantas perspectivas, ¿Por qué asumimos, en este trabajo, una mirada a aspectos históricos, en lo que se refiere al cine y la educación? Comprendemos, así como Gabriela Augustowsky (2017) que el establecimiento de principios de un enfoque, en la contemporaneidad, del cine y del audiovisual, implica necesariamente el saber histórico.

\section{Algunas palabras finales...}

En cada tiempo y lugar, "un complejo conjunto de intenciones, teorías, prácticas y valores guía las tendencias pedagógicas" (Arslan; Iavelberg, 2013, p. 1). Esto se aplica tanto a la educación general como a la especificidad de la enseñanza del arte, contribuyendo "a la comprensión de cómo los centros de decisión y discusión, las redes escolares, los grupos de educadores o las escuelas incorporan los paradigmas educativos y organizan sus prácticas" (Arslan; Iavelberg, 2013, p. 1).

Como dijimos al principio de este artículo, la defensa para la introducción del cine, en el campo educativo, se produjo a partir de diferentes comprensiones de este lenguaje artístico, entre las que se destaca la idea del cine como un importante instrumento educativo, desde una visión aliada a la modernización de la educación, en la primera mitad del siglo XX, en Brasil.

Al subrayar el papel de la poetisa y educadora Cecilia Meireles en este trabajo, lo hacemos como una forma de dar visibilidad a su comprensión del cine y sus relaciones con la educación. Para ella, la presencia de este lenguaje artístico en 
LIMA / El cine y la enseñanza del arte en Brasil: una mirada a concepciones y experiencias modernistas.

entornos educativos se entendía como una forma de llevar a los estudiantes a "aprender viendo", es decir, hacía hincapié en las potencialidades de las imágenes, fijas o en movimiento, como fundamentales para el proceso de enseñanza y aprendizaje. Aquí es importante destacar, la enseñanza y el aprendizaje, no del cine - arte - en sí mismo, sino como um camino de formar una cultura visual, como una herramienta instructiva, como una posibilidad educativa para enseñar a los estudiantes a "apreciar" las imágenes, su entorno, el mundo en el que podría pasar a actuar.

Con el énfasis en el "Curso Intensivo de Arte na Educação (CIAE)" de la "Escolinha de Arte do Brasil" (EAB), procuramos destacar la presencia del cine e sus formas de insertar este lenguaje en la formación de los profesores de arte. ¿Qué cambios conceptuales y prácticos, en relación con el cine en la educación, se pueden señalar de esta experiencia?

A partir de la segunda mitad del siglo XX, en el contexto del Curso Intensivo, el cine es tan importante como otros lenguajes artísticos em el proceso de formación de profesores de arte del curso. Es importante señalar que un especialista en cine, como destacamos, se encarga de las actividades teóricas y prácticas de este curso, característica que pone de relieve la importancia del cine para la formación de los profesores de arte en el CIAE.

En nuestra lectura, el cine fue entendido (y trabajado) como una herramienta para el desarrollo de la capacidad creativa de los profesores que participaron del CIAE. Las acciones implicaban "ver" y "leer" películas como una forma de aprender las artes, incluyendo el cine.

Al destacar el cine y las propuestas de formación del CIAE lo hacemos como una posibilidad de, a través de las "brechas" de la historia, dar visibilidad a las diferentes formas de expresión artística por las cuales se trabajó en el curso, una experiencia muy importante en la historia de la enseñanza de las artes en Brasil, responsable de la formación de diferentes generaciones de profesores de artes (principalmente en las décadas de 1960 y 1970) y que, desde el presente, vislumbramos como precursora en el trabajo con el cine en la formación de especialistas en el campo del arte y educación.

\section{Referencias}

Almeida, R. (2017). Cinema e educação: fundamentos e perspectivas. Belo Horizonte: Educação em Revista. Belo Horizonte, 33, 1-28.

Arslan, L. M.; Iavelberg, R. (2013). Ensino de arte. São Paulo: Cengage Learning. 
Augustowsky, G. (2017). La creación audiovisual en la infância: de espectadores a produtores. Ciudad Autonoma de Buenos Aires: Paidós.

Azevedo, F. A. G. (2000). Movimento Escolinhas de Arte: em cena memórias de Noemia Varela e Ana Mae Barbosa. Dissertação de mestrado, São Paulo: ECAUSP, 2000.

Barbosa, A. M. (2015). Redesenhando o desenho: educadores, política e história. São Paulo: Cortez.

Catelli, R. E. (2005). Cinema educativo, 1920-1930: a educação das massas e a educação do cinema nacional. Intexto, Porto Alegre: UFRGS, v. 1, n. 12, p. 1-15.

Costa, Fabíola C. B. (1990). Escolinha de Arte de Florianópolis: 25 anos de atividade arteleducativa. Florianópolis: FCCEDIÇÕES.

Didi- Huberman, G. (2008). Cuando las imágenes toman posición. Madrid: Machado Libros.

Dussel, I. (2014). Educar la mirada. Reflexiones sobre una experiencia de producción audiovisual y de formación docente En Dussel, I.; Gutierrez (comp.) Educar la mirada: políticas y pedagogías de la imagen. Buenos Aires: Manantial: Flacso, OSDE, p. 277-294.

Dussel, I. (2014). Usos del cine en la escuela: una experiencia atravessada por la visualidade. Estudos da língua(gem): Vitória da Conquista, v. 12, n 1, p. 77-100.

Fabris, E. H. (2008). Cinema e Educação: um caminho metodológico. Educação e Realidade, Porto Alegre, v. 33, n. 1, p. 117-134.

Filho, V. F. (1941). A educação e seu aparelhamento moderno. São Paulo/ Rio de Janeiro/ Recife/Porto Alegre: editora nacional.

Frange, Lucimar Bello P. (2001). Noêmia Varela e a Arte. Belo Horizonte: Editora C/Arte.

Hilsdorf, M. L. S. (2015). História da educação brasileira: leituras. São Paulo: Cengage learning.

Lima, S. P. F. (2019). Escolinha de Arte do Brasil: algunas ressonâncias. Revista Rebento, 11, 148-165. São Paulo.

Lima, S. P. F. (2014). Escolinha de Arte de São Paulo: instantes de uma história. Dissertação de Mestrado. São Paulo: IA-UNESP.

Lima, S. P. F. (2012) de. Escolinha de Arte do Brasil: movimentos e desdobramentos. Rio de Janeiro: Associação Nacional de Pesquisadores em Artes Plásticas (ANPAP). 
LIMA / El cine y la enseñanza del arte en Brasil: una mirada a concepciones y experiencias modernistas.

Lima, S. P. F. (2017a). O Curso Intensivo de Arte na Educação (CIAE) e a formação de arte-educadores no Brasil: história e memória. Anais do XXVI Encontro da Associação Nacional de Pesquisadores em Artes Plásticas: Memórias e inventações. (Orgs.) Luisa Angélica Paraguai, Milton Terumitsu Sogabe, Paula Cristina Somenzari Almozara, Regilene Aparecida Sarzi Ribeiro.- Campinas: ANPAP, PUC- Campinas.

Lima, S. P. F. (2017b). Tom Hudson e os cursos de educação criadora na Escolinha de Arte do Brasil. Anais do XXVI Encontro da Associação Nacional de Pesquisadores em Artes Plásticas: Memórias e inventações/ (Orgs.) Luisa Angélica Paraguai, Milton Terumitsu Sogabe, Paula Cristina Somenzari Almozara, Regilene Aparecida Sarzi Ribeiro.- Campinas: ANPAP, PUC- Campinas, 2017 . ISSN: 2175-821

Lispector, C (1998). Água Viva. São Paulo: Rocco.

Mate, C. H. (2010). Didática e história: encontros possíveis. Tese de Livre docência. São Paulo: Faculdade de Educacão, Universidade de São Paulo.

Varela, N. (1972). Criatividade na escola e a formação do professor. Arte\&Educação. Rio de Janeiro: Escolinha de Arte do Brasil, n 12, julho, 1972.

Varela, N. (1986). A formação do arte/educador no Brasil. In: Barbosa, Ana Mae. História da Arte/Educação: a experiência de Brasília. São Paulo: Max Limonad, p. 11- 27. 